\title{
Basic Training of Student's Outdoor Club Increases Muscle Mass after Five Weeks of Exercise in Males
}

\author{
Novie Salsabila ${ }^{1}$, M. Rizal Chaidir ${ }^{2}$, Setiawan $^{3}$ \\ ${ }^{1}$ Faculty of Medicine, Universitas Padjadjaran, ${ }^{2}$ Department of Orthopaedic and Traumatology, \\ Faculty of Medicine, Universitas Padjadjaran/Dr. Hasan Sadikin General Hospital, Bandung, \\ ${ }^{3}$ Department of Physiology, Faculty of Medicine, Universitas Padjadjaran
}

\begin{abstract}
Background: Aerobic and anaerobic exercises, may lead to increase muscle mass. The aim of this study was to determine the change in muscle mass during basic training of students' outdoor club.

Methods: This was an observational analytic study to college students who joined basic training of students' outdoor club for 19 weeks. Subjects consisted of 17 male and 15 female students, measured five times consecutively by using Body Fat/Hydration monitor scale, with Bioelectrical Impedance Analysis principle. Data collection was performed five times, from February to July 2012 in Bandung. Statistical analysis was processed using Analysis of Variance (ANOVA).

Results: The result in males showed the mean $43.35 \pm 3.15$ on the initial measurement. The muscle mass further increased significantly after five, ten, fifteen, and nineteen weeks of exercise $(43.73 \pm 3.18(p<0.05)$; $44.07 \pm 2.97(\mathrm{p}<0.05) ; 44.08 \pm 2.84(\mathrm{p}<0.05) ; 44.72 \pm 2.78(\mathrm{p}<0.05)$; all data vs 43.35 \pm 3.15$)$ respectively. In females, there was increased of muscle mass although not all were statistically significant. The baseline was $37.77 \pm 2.00$ with increased muscle mass after five, ten, fifteen, and nineteen weeks of exercise $(37.78 \pm 2.06$ $(\mathrm{p}>0.05) ; 38.08 \pm 1.67(\mathrm{p}>0.05) ; 38.23 \pm 1.52(\mathrm{p}>0.05) ; 38.61 \pm 1.52(\mathrm{p}<0.05)$ vs $37.77 \pm 2.00)$ respectively. Conclusion: Basic training of student's outdoor club increases muscle mass significantly after five weeks of exercise in males, but not in females
\end{abstract}

Key words: Basic training, Bioelectrical Impedance Analysis, hypertrophy, muscle mass, students outdoor club

\section{Introduction}

Physical activity is a programmed, structured, and repetitive body movement. 1 Sport is defined as a physical activity which is done to increase health or improve deformity.2 Sport is characterized by the differences in intensity, frequency, duration, and type.3 Those characters influence the adaptation of human body to sport, such as muscle hypertrophy.4-6 Hypertrophy is a condition of increasing muscle mass.7 Based on the intensity, exercise is classified as mild (less than $50 \%$ maximum heart rate), moderate (50-85\% maximum heart rate), and heavy (more than $85 \%$ maximum heart rate). While maximum heart rate is defined as 220 minus age.8

This article reports the result of the study that determined the increase of muscle mass after 19 weeks of exercise.

\section{Methods}

The subjects of this study were college students who joined basic training of a students' outdoor club. All of the subjects had been exercising for 19 weeks. They were included in this study after they agreed to participate as a subject in this study. On the other hand, they would be excluded if they had injury or the data needed were not completely collected. Data collection was performed five times, starting from February to July 2012 in Bandung.

After receiving explanation about this study, and filling an informed consent letter, the subjects were included in 19 weeks of exercise. Data collection was performed 5 times during the exercise, in the beginning, fifth week, tenth week, fifteenth week, and nineteenth week of exercise. Data collection was performed

Correspondence: Novie Salsabila, Faculty of Medicine, Universitas Padjadjaran, Jalan Raya Bandung-Sumedang Km.21, Jatinangor, Sumedang, Indonesia, Phone: Phone : +62 85721450929 Email: salsabila.novie@gmail.com 
five times because of differences in intensity exposure that was given in each period. The exposure given in this study started from low to moderate intensity in the first five weeks. In the second period, the intensity was from moderate to heavy. In the third period, tenth to fifteenth week, exercise was performed with moderate intensity. In the fifteenth to nineteenth week, exercise was perfomed with heavy intensity.

Total sampling method was used to determine the number of samples. A total of 32 subjects were included. Subjects were divided into 2 groups, based on the sex. Muscle mass was defined as muscle proportion of individual's total body weight measured by Body Fat/Hydration monitor scale, designed to measure the composition of fat, water, and muscle of the body by using the Bioelectrical Impedance Analysis.

The outcome of this study was the change of mean muscle mass from the baseline measurement. Used as baseline for this study was the muscle mass determined in the first week, before any exposure was given. Data was processed using theSPSS 17.0 version, and thestatistical analysis was carried out using analysis of variance (ANOVA).

\section{Results}

Out of 47 subjects who fully participated in the basic training, there were 32 subjects who met the criteria for this study. Twelve college students were excluded because of incomplete data collection. From those 32 subjects, 17 were male, with mean of age 19.18 ( \pm 1.131$)$, and the remaining were female with mean of age $19.47( \pm 0.743)$.

In male overall, there was a difference in the effect to increasemuscle mass with variations of intensity. The exposure given in this study started from low to moderate intensity in the first five weeks. In this period, muscle mass increase was not as big as in the second period, of which intensity was moderate to heavy. In the third period, tenth to fifteenth week, exercise was aimed to maintain the physical condition, by moderate intensity exercise. In the fifteenth to nineteenth week, exercise was with heavy intensity. In this last week, there was high increase in muscle mass compared with the periods before.

The mean of muscle mass in the first measurement which was settled as baseline was $43.35 \pm 3.15$ percent. There was a substantial increase in muscle mass in every period of measurement, especially in the last week ( $p=0.000$ vs baseline) (Figure 1 ).

The baseline measurement of female subjects was $37.77 \pm 2.00$ percent, and mean of muscle mass also increased in every measurement, but with statistical significance only in the last week of measurement ( $p=0.025$ vs baseline).

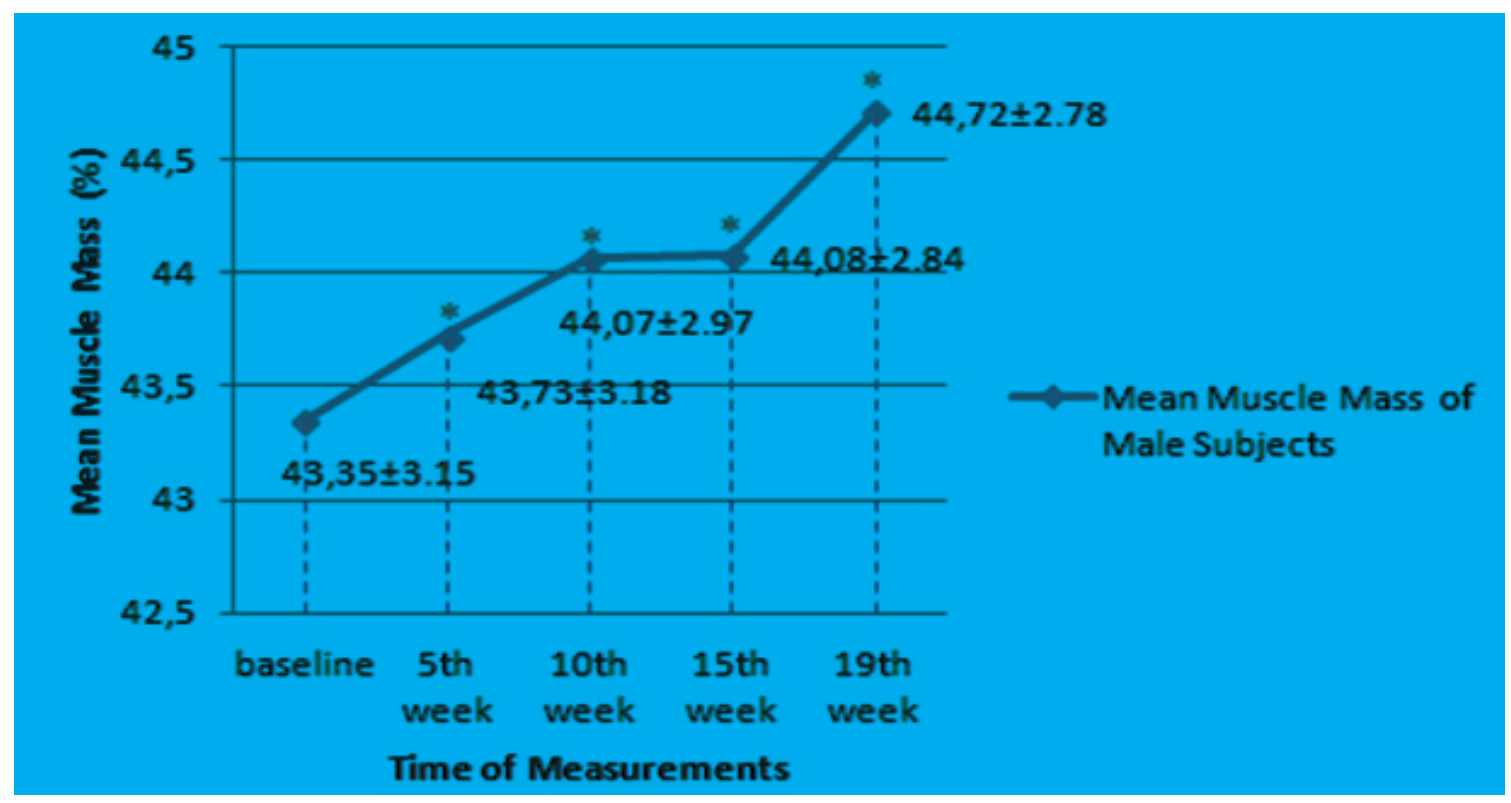

Figure 1 Average Profile of Muscle Mass in Male Subject

Description : * statistically significant compared to baseline 


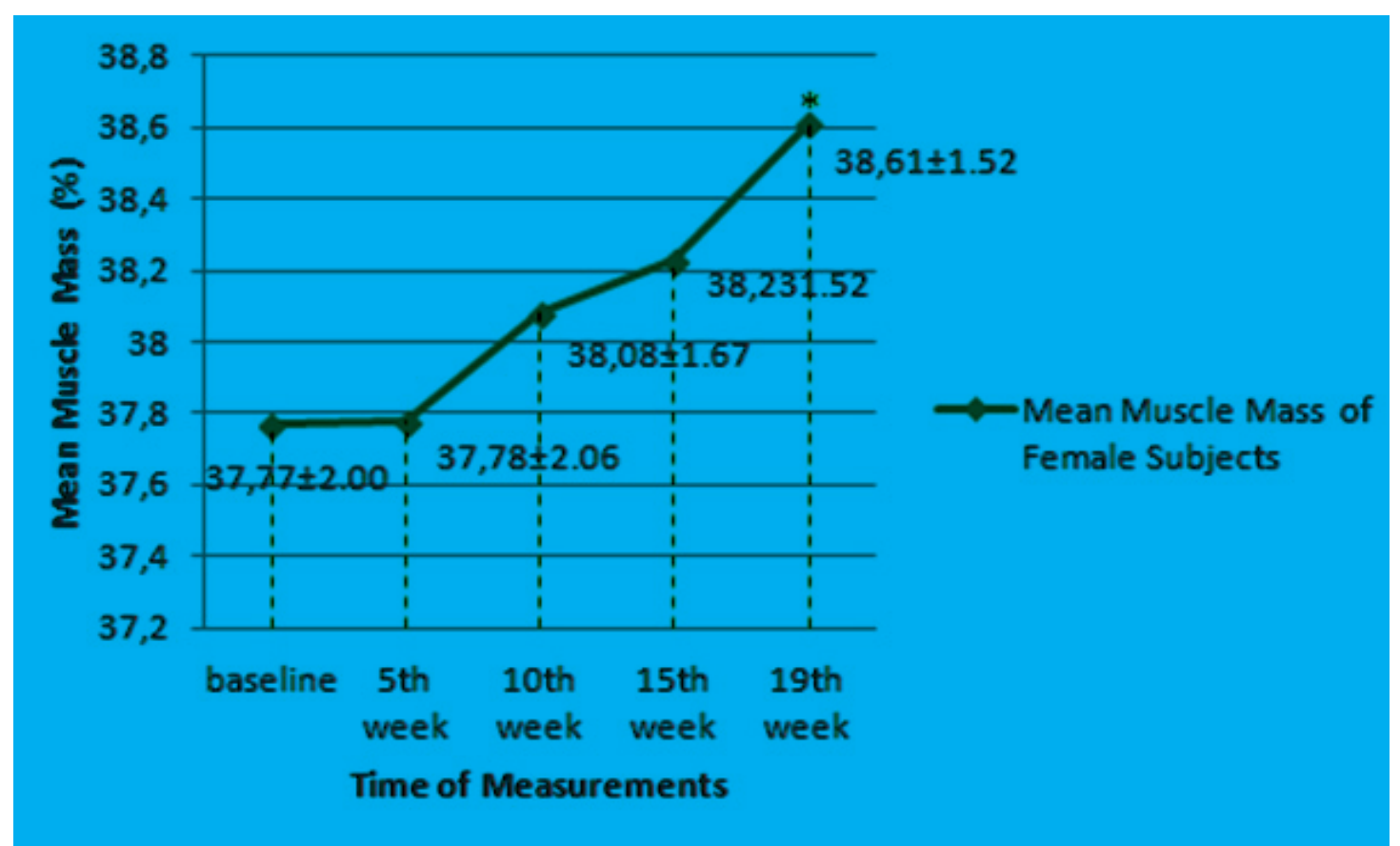

Figure 2 Muscle Mass Profile on Female Subjects

Description : * statistically significant compared to baseline

\section{Discussions}

The result of this study showed that there was statistically significant increase in muscle mass of male subjects receiving 19 weeks of training. This result proved that exercise influenced muscle mass. A study that was held by Villareal et al.10, had similar result. The subjects in that study were adults with obesity, who were given aerobic exercises such as upstairs-downstairs, treadmill, and stationary cycling for 52 weeks with increasing intensity periodically.

One mechanism of increasing muscle mass is hypertrophy, although still in controversy, hyperplasia might also occur. In a person who performs exercise, there is an increasing amino acid transport to muscle cell as a respond to pressure. Amino acid is then rearranged to form contractile protein. Contractile protein increases amount and size of myofibril.7

Growth hormone/insulin-like growth factor-1 (GH/IGF-1) and fibroblast growth factor-2 (FGF-2) influence growth. Exercise increases the level of GH/IGF-1 and FGF-2. FGF2 is responsible for myogenesis and capillary angiogenesis during muscle growth. The IGF-1 maintains muscle mass by suppressing protein degradation, increasing uptake of amino acid, and also stimulating protein synthesis. Protein IGF-1 influences GH in protein synthesis by increasing amino acid uptake, also reducing the time needed for transcription and translation of mRNA.7, 11 Beside that, IGF1 also has an effect on calcineurin pathway. Calcineurin induces translocation of nuclear factor of activated T-cells (NFAT), the substance that influences growth of skeletal muscle. In muscle with hypertrophy, there is an increasing level of enzymes in mitochondria. This enzyme synthesizes ATP, that has a role in cross bridging of contractile protein when contraction occur.12, 13

The muscle increase in glycogen is stored as respond to exercise.14 Glycogen is used when there is not enough glucose as energy source.15 The other local adaptation is the shifting source of energy, from carbohydrate to fat. Using fat as energy source decreases the amount of fat deposit in the body. Muscle and fat are body components, so decreased in fat stored in the body will increase proportion of muscle mass.7

In this study, there was no statistically significant result in female, except after the last week of measurement. Basically, female subjects also experiences similar adaptation like in male. The difference between male and female is the hormonal system since male's level of testosterone is more than female's. Testosterone induces transcription, translation, and synthesis of protein in target 
cell. Besides that testosterone has an anabolic function that stimulates structural protein synthesis in skeletal muscle and prevents its degradation. This function causes increasing protein deposit, especially in muscle cells.7, 16,17

On the other side,, estrogen has an effect on fat deposit. Estrogen stimulates the uptake of lipoprotein serum, and causes the decrease in total cholesterol and LDL serum level, increase level of HDL and triglyceride in serum, and decrease lipoprotein A serum. Females have more estrogen level, leads to more fat deposit than males, rather than anabolic effect.7

\section{References}

1. Whitney E, Rolfes SR. Understanding nutrition. 11th ed. Belmont: Thomson Wadsworth; 2008

2. Dorland, Newman WA. Dorland's pocket medical dictionary. 28th ed. Philadelphia: Elsevier Saunders; 2009

3. American College of Sport Medicine. Cardiorespiratory training guidelines. ACSM: Indianapolis; 2011

4. Volpe SL, Rife FN, Melanson EL, Merritt A, Witek J, Freedson PS. Physiological Changes in Sixth Graders Who Trained to Walk the Boston Marathon. J Sports Med. 2002;1:128-35.

5. Seynnes OR, Boer Md, Narici MV. Early skeletal muscle hypertrophy and architectural changes in response to high-intensity resistance training. J Appl Physiol. 2007;102(1):368-73.

6. Tesch P, Trieschmann J, Ekberg A. Hypertrophy of chronically unloaded muscle subjected to resistance exercise. J
Appl Physiol. 2004;96(4):1451-8.

7. Guyton AC, Hall JE. Textbook of medical physiology. 12th ed. Philadelphia: Elsevier Saunders; 2010

8. Slentz CA, Duscha BD, Johnson JL, Ketchum K, Aiken LB, Samsa GP, et al. Effects of the amount of exercise on body weight, body composition, and measures of central obesity. Arch Intern Med. 2004;164(1):319

9. Manual Instruction of Body Fat/Hydration Monitor Scale. Perfect Health; 2009

10. Vilareal DT, Chode MDS, Parimi N. Weight loss, exercise, or both and physical function in obese older adults. N Engl J Med. 2011;364(13):1218-29.

11. Gardner D, Shoback D.Greenspan's basic and clinical endocrinology. 9th ed. San Fransisco: McGraw-Hill Companies: 2011.

12. Wackerhage $H$, Woods NM. Exerciseinduced signal transduction and gene regulation in skeletal muscle. J Sports Med. 2002;1:103-4.

13. Barrett KE, Barman SM, Boitano S, Brooks H. Ganong's review of medical physiology. 23rd ed. San Fransisco: McGraw-Hill Companies; 2009.

14. Murray RK. Harper's illustrated biochemistry. 28th ed. San Fransisco: McGraw-Hill Companies; 2009.

15. Baar K, Wende AR, Jones TE, Marison M, Nolte LA, Chen M, et al. Adaptations of skeletal muscle to exercise: rapid increase in the transcriptional coactivator PGC-1. FASEB J. 2002;16(14):1879-86.

16. Molina P. Endocrine physiology. 3rd ed. San Fransisco: McGraw-Hill Companies; 2009.

17. Silbernagl S, Despopoulos A. Color atlas of physiology. 6th ed. New York: Thieme; 2009. 